\title{
Performance of RegCM4.5 in Simulating the Regional Climate of Western Tianshan Mountains in Xinjiang, China
}

\author{
Quanying Cheng ${ }^{1,2}$ and Fan $\mathrm{Li}^{3,4,5, *}$ \\ 1 State Key Laboratory of Resources and Environmental Information System, Institute of Geographic Sciences \\ and Natural Resources Research, Chinese Academy of Sciences, Beijing 100101, China; \\ chengqy.18b@igsnrr.ac.cn \\ 2 College of Resources and Environment, University of Chinese Academy of Sciences, Beijing 100049, China \\ 3 Institute of Forest Resource Information Technique, Chinese Academy of Forestry, Beijing 100091, China \\ 4 Jiangsu Key Construction Laboratory of IoT Application Technology, School of Internet of Things \\ Engineering, Wuxi Taihu University, Wuxi 214064, China \\ 5 National Mobile Communications Research Laboratory, School of Information Science and Engineering, \\ Southeast University, Nanjing 211189, China \\ * Correspondence: lifan@ifrit.ac.cn
}

Citation: Cheng, Q.; Li, F.

Performance of RegCM4.5 in

Simulating the Regional Climate of

Western Tianshan Mountains in

Xinjiang, China. Atmosphere 2021, 12,

1544. https://doi.org/10.3390/

atmos12121544

Academic Editors: Zengyun $\mathrm{Hu}$,

Xuguang Tang and Qinchuan Xin

Received: 27 October 2021

Accepted: 20 November 2021

Published: 23 November 2021

Publisher's Note: MDPI stays neutral with regard to jurisdictional claims in published maps and institutional affiliations.

Copyright: (c) 2021 by the authors. Licensee MDPI, Basel, Switzerland. This article is an open access article distributed under the terms and conditions of the Creative Commons Attribution (CC BY) license (https:/ / creativecommons.org/licenses/by/ $4.0 /)$.

\begin{abstract}
The western Tianshan Mountains region in China has a complex topography where basins, mountains and glaciers co-exist. It is of great significance to study the sensitivity of meteorological factors in this region to different parameterization schemes of climate models. In this paper, the regional climate model RegCM4.5 is used to simulate the meteorological factor (mean temperature, maximum temperature, minimum temperature, precipitation and wind speed) occurring in the western Tianshan Mountains region from 2012 to 2016, so as to investigate the effects of different cumulus convective schemes (Grell, Tiedtke and Emanuel), including land cumulus convective schemes (LCCs) and ocean convective schemes (OCCs) on annual and seasonal simulations of meteorological factor by using the schemes of RUN1 (Grell for LCC and Tiedtke for OCC), RUN2 (Tiedtke for LCC and Emanuel for OCC), RUN3 (Grell for LCC and Emanuel for OCC) and ENS (the ensemble of RUN1, RUN2 and RUN3). The results show that the simulations of annual and seasonal meteorological factors are not significantly sensitive to the combination of LCCs and OCCs. In the annual simulations, RUN2 scheme has the best simulation performance for the maximum, average and minimum temperatures. However, other schemes of precipitation simulation outperform RUN2 scheme, and there is no difference among the four schemes for wind speed simulation. In the seasonal simulations, RUN2 scheme still performs well in the simulation of the average, maximum and minimum temperatures for four seasons, except for the simulation of the average temperature in spring and summer. For the simulation of the maximum temperature in summer, RUN2 scheme performs the same as ENS. For the simulation of other seasons, different meteorological factors have different performances in four seasons. Overall, the results show that different combinations of cumulus convection schemes can improve the simulation performance of meteorological factors in the western Tianshan Mountains of Xinjiang.
\end{abstract}

Keywords: regional climate model; RegCM4.5; western Tianshan Mountains; parameterization scheme

\section{Introduction}

Located in the hinterland of Eurasia, Xinjiang is the largest province with the longest border line and the largest number of neighbors in China, and it has become the most convenient access to Central Asia from the Chinese mainland. It is a very important region in Asia. Xinjiang has a temperate continental climate, characterized by large temperature differences and abundant sunshine, but little precipitation and a dry climate. The presence of Tianshan Mountains divides Xinjiang into two parts: the north and the south. The complex topography of western Tianshan Mountains in Xinjiang, where basins, hills and 
glaciers co-exist, has an important influence on the formation of climate in Xinjiang, China. Although Xinjiang is generally deep inland and far from the sea, and the climate types are all temperate continental, there are still significant differences in climate between the southern and northern Xinjiang. Accurate modeling and prediction of the climate in the region is important to address climate change [1,2].

At present, an important means of climate research is simulation by climate model, which mainly includes global climate models (GCMs) and regional climate models (RCMs). GCMs are not directly applicable to regional simulations due to the large differences in resolution between the grid spacing and the end-user's needs. Therefore, RCMs are widely used for regional simulation due to their high resolution [3-5]. However, the proper selection of horizontal resolution, land surface models [6,7] and convective parameterization schemes (CPS) $[8,9]$ remains problematic, and their selection mostly relies on empirical study. Many studies have shown different simulation results using different CPS $[10,11]$ for the same region. The comparison of the simulated near-surface temperature with observational data over the European region indicates a cold bias with both Grell scheme configurations, but the bias can be reduced when the Emanuel convective scheme is applied, and the simulated precipitation is not systematically positive in the southern part of Eastern Europe [12]; Tchotchou and Kamga found that monsoonal precipitations are sensitive to the choice of cumulus parameterization and closure schemes in West Africa [13]; Raju's research results reveal that the mixed convective scheme responds better to the simulation of precipitation and temperature over the Indian subcontinent, and the circulation features and the annual cycle of precipitation and temperature are also well simulated with the mixed convection scheme [14]. The authors of ref. [15] found that the Emanuel scheme shows an overall overestimation of precipitation in China, while the other three CPSs overestimate only in northern and northwestern China, and seasonally, the Tiedtke scheme simulates the best annual variability of precipitation in China compared with the others CPSs. In the RegCM4 version, the CPSs are described in more detail in two parts, and it is able to run different convection schemes over land and ocean. Studies have shown that different CPSs have different simulation performance over different regions, especially in land and sea areas. Bhatla's research found that out of six CPSs, Tiedtke and Mix99 (Grell over land and Emanuel over ocean) correctly simulated the onset date, and they also found that the Mix99 CPSs performed well in simulating the synoptic features during the monsoon phases. Existing research shows that these physical processes cannot be accurately simulated over the entire Earth. Choosing an appropriate convective parameterization scheme (CPS) in RCMs is critical for region simulations [16-18], as it allows to simulate the region in a more refined way. At the same time, the annual and seasonal climate simulations are also very important for determining short-term adaptation measures $[19,20]$.

In this paper, we apply the Regional Climate Model version 4.5 (RegCM4.5) to the western Tianshan Mountain area in China. The objective of this study is to evaluate the performance of three mixed CPSs and their ensemble averages, namely, Grell over land and Tiedtke over ocean (RUN1), Tiedtke over land and Emanuel over ocean (RUN2), and Grell over land and Emanuel over ocean (RUN3), with the ensemble being the average of RUN1, RUN2 and RUN3. The remainder of this paper is organized as follows. Section 2 provides a brief description of the model and three convection schemes. Section 3 presents the experimental design and Section 4 describes the results and discusses the sensitivity experiments with different convection schemes. Section 5 discusses the results and summarizes the conclusion.

\section{The Convective Parameterization Schemes}

\subsection{Grell Scheme}

Grell's [21] convective scheme is based on the Fritsch-Chappell (FC) assumption [22]. The scheme applies a simple cloud model assuming that the large amount of flux in the upstream and downstream is constant with the height, and that the original level of upstream and sinking air flow are given by the maximum and minimum ambient humid static energy, 
respectively. The scheme is activated when the parcel finally reaches the wet convection from the original horizontal up-draft. A large amount of flux $\left(\mathrm{m}_{0}\right)$ in the downdraft is proportional to the updraft $\left(\mathrm{m}_{\mathrm{b}}\right)$, and it is calculated by the following relationship.

$$
\mathrm{m}_{0=} \frac{\beta \mathrm{I}_{1}}{\mathrm{I}_{2}} \mathrm{~m}_{\mathrm{b}}
$$

$I_{1}$ is the condensed normalized updraft, $I_{2}$ is the evaporative normalized downdraft, $\beta$ is a small part of the re-evaporation of updraft condensate during the descent and depends on the change in the wind direction and varies mainly between 0.3 and 0.5 . Hence, the equation is as follows:

$$
\mathrm{P}^{\mathrm{CU}}=\mathrm{I}_{1} \mathrm{~m}_{\mathrm{b}}(1-\beta)
$$

where $\mathrm{P}$ is precipitation. The meanings of other parameters are shown in Formula (1).

\subsection{Tiedtke}

Tiedtke is a mass flux and moisture convergence scheme originally designed for global climate models with special attention to the correct display of deep tropical convection. Tiedtke consists of three types of convection. Only one type of convection is allowed per step in each grid, and the collection of clouds appearing in each type of convection is assumed by the updraft and downdraft. The Tiedtke scheme considers only one ascent and descent of the overall airflow, which is equivalent to the ascent and descent of all cumulus monomer airflows in the grid. In the actual simulation, deep or shallow convection occurs when there is an unstable convection on the cloud base with a large-scale increase. Assuming that no deep or shallow convection can occur, then mid-stream convection is applied.

\subsection{Emanuel}

The Emanuel scheme assumes that interactions in the cloud are random and nonuniform, and increases convective fluxes based on an idealized condition of sub-cloud-scale downdrafts and updrafts, and the convection model is activated when the cloud base level is below the height of the neutral buoyancy layer. Assuming that clouds and the mixture of ambient air are mixed in a uniform spectrum, when the air rises between the cloud base and the zero-buoyancy layer, the condensed water vapor partly forms precipitation and the rest forms clouds. The Emanuel scheme incorporates the automatic conversion formula for clouds and water, and sets the water content of the initial cloud in the formula to a temperature-related function, in order to take into account the microphysical process of cloud ice, which is added to a single downdraft that is hydrostatic and unsaturated and carries water and heat when precipitation is generated.

\section{Model and Experimental Design}

\subsection{Description of the RegCM Model}

RegCM is regional climate model developed by Abdus Salam International Center for Theoretical Physics. The first version of RegCM was developed in the late 1980s [23,24], which has since then been upgrades to RegCM2 [25], RegCM3 [26] and RegCM4 [27]. The dynamical core of the RegCM model is similar to the hydrostatic version of the mesoscale model MM5 [28]. The PBL computations are parameterized by using the scheme of Holtslag et al. [29], the land surface model is the Biosphere-Atmosphere Transfer Scheme (BATS) and the Community Land Model (CLM) [30] schemes, and the radiation scheme is the modified NCAR Community Climate Model version 3 (CCM3) [31]. The model used here is RegCM4.5, which has many upgrades in the model physics. One of the main enhancements in this version of the model is the ability to run different convection schemes over land and ocean, also known as 'mixed convection'. Many studies have shown that different schemes have different performance over different regions, especially over 
land versus ocean areas, and it currently includes three options for representing cumulus convection [32].

The scheme of Grell is the implementation of Giorgi [33]. The other two schemes are Tiedtke [34] and Emanuel scheme [35,36]. In this paper, we apply a combination of the three schemes to simulate the meteorological factors when other parameters are consistent, describe the following Table 1, where ENS is the average of the three schemes RUN1, RUN2 and RUN3, and icup_lnd and icup_ocn are the cumulus parameterization schemes that must be set before the model simulation.

Table 1. Parameterization scheme.

\begin{tabular}{ccc}
\hline Schemes & icup_lnd & icup_ocn \\
\hline RUN1 & Grell & Tiedtke \\
RUN2 & Tiedtke & Emanuel \\
RUN3 & Grell & Emanuel \\
ENS & Ensemble_mean & Ensemble_mean \\
\hline
\end{tabular}

\subsection{Experimental Design and Data Check}

The model domain covers the western Tianshan Mountain region in Xinjiang $\left(36^{\circ}-50^{\circ} \mathrm{N}\right.$, $70^{\circ}-100^{\circ} \mathrm{E}$ ), as shown in Figure 1. The grid center of the simulated area is located at $43.15^{\circ} \mathrm{N}, 82.88^{\circ} \mathrm{E}$. A model grid with a horizontal resolution of $20 \mathrm{~km}$ is selected for the simulation experiments. The number of grid cells is $121 \times 100$ (East-West $\times$ North-South). The reanalysis data from the National Centers for Environmental Prediction and National Center for Atmospheric Research (NCEP\&NCAR) are selected as the initial field and side boundary values of the model $[37,38]$. The dynamic module uses MM4 frame, with a step size of $6 \mathrm{~h}$ for the model output. The experiment was conducted for a period of four years from 1 January 2012 to 31 December 2016. The results of the model-driven data from January 2012 are used as model spin-up, and therefore are not analyzed. The observations used for comparison with the model were based on the daily terrestrial climate datasets from 66 sites in the western Tianshan Mountains of Xinjiang provided by the China Meteorological Data Network (http:/ / data.cma.cn, accessed on 12 March 2017), which are continuous observation data, and the triangles in Figure 1 show the locations of the 66 observation sites.

\subsection{Verification Method}

\subsubsection{Correlation Coefficient}

According to the existing analysis methods [39,40], the results are analyzed by calculating the correlation coefficient and root mean square error between the model simulated value and the observed value. The correlation coefficient is defined as follows:

$$
\text { CORREL }=\frac{\sum_{\mathrm{i}=1}^{\mathrm{N}}\left(\mathrm{x}_{\mathrm{i}}-\overline{\mathrm{x}}\right)\left(\mathrm{y}_{\mathrm{i}}-\overline{\mathrm{y}}\right)}{\sqrt{\sum_{\mathrm{i}=1}^{\mathrm{N}}\left(\mathrm{x}_{\mathrm{i}}-\overline{\mathrm{x}}\right)^{2} \sum_{\mathrm{i}=1}^{\mathrm{N}}\left(\mathrm{y}_{\mathrm{i}}-\overline{\mathrm{y}}\right)^{2}}}
$$

In the above formula, $x_{i}$ and $y_{i}$ are the simulated values and observed values in the same position, $\bar{x}$ and $\bar{y}$ are their average values, $N$ represents the number of grid points.

\subsubsection{Root Mean Square Error}

The root mean square error (RMSE) reflects the average deviation between the simulations and observations, which is a trade-off standard of the total error and is one of the ways to reflect the simulation performance. Typically, the greater the root mean square error is, the lower the accuracy, and in turn, the higher the simulation accuracy would be. The root mean square error formula is defined as follows:

$$
\operatorname{RMSE}=\sqrt{\frac{\sum_{\mathrm{t}=1}^{\mathrm{N}}\left(\mathrm{Sim}_{\mathrm{t}}-\mathrm{Obs}_{\mathrm{t}}\right)^{2}}{\mathrm{~N}}}
$$


In the above formula, $\mathrm{Sim}_{\mathrm{t}}$ stands for the simulation results of RegCM4.5, $\mathrm{Obs}_{t}$ is the actual observation value, and $\mathrm{N}$ represents the number of grid points.

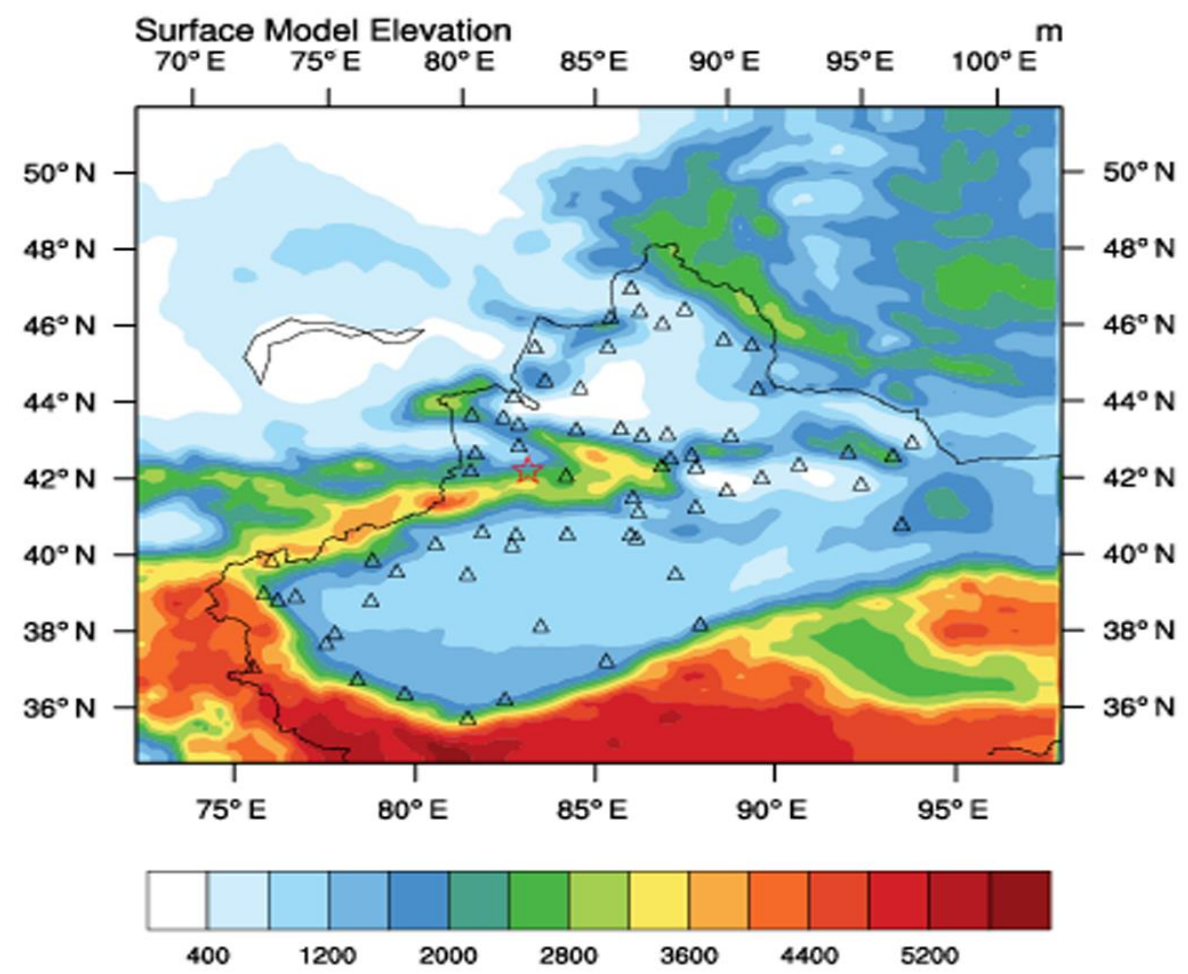

Figure 1. RegCM simulated surface model and the area. The black lines are the simulation area, the pentagram is the center point of the simulation and the triangles are the locations of the 66 observation sites.

\section{Results and Discussion}

\subsection{Annual Simulation and Inspection}

\subsubsection{The Analysis of Annual Temperature}

It can be seen from Figure 2 that the three parameterization schemes and sets of the model have a good simulation effect on the temperature distribution in the western Tianshan Mountains of Xinjiang, and there is no significant difference between the simulated and observed values using different schemes, indicating that the annual average temperature in the western Tianshan Mountains of Xinjiang is not sensitive to different parameterization schemes of the model. The temperature decreases from the center of the region to the border, which is consistent with the climate change in the basin. Meanwhile, a small part of the central and western regions has lower temperatures. Compared with the simulated elevation results in Figure 1, it can be seen that the higher altitude of this small part of the region leads to lower temperatures, and the simulation result is consistent with the actual situation. From the whole simulation area, the temperature in the north is lower than that in the south, which reflects the temperature difference between the north and the south. Comparing the northern and southern parts of the region, it can be seen that the difference between the simulated and observed values in the south is not obvious, and the simulation results are better, while the difference between the simulated values and the observed values in the north is more obvious, and the difference is greater the further north, which indicates that the model simulates the temperature better in the south of Tianshan Mountains in Xinjiang than in the north. 

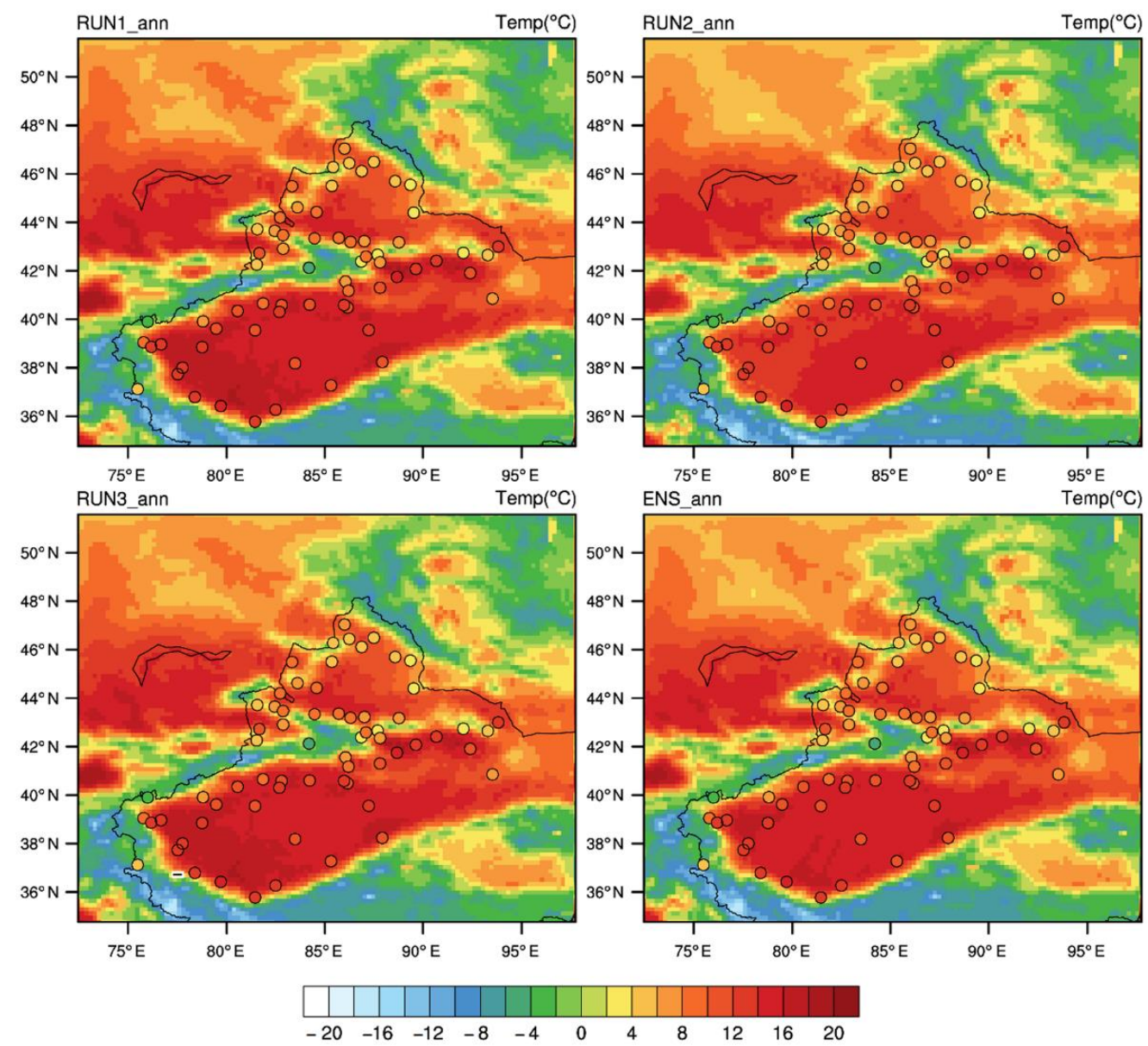

Figure 2. Comparison between simulation and observation of annual average temperature using four cumulus parameterization schemes, where the circles are observed values, the rest are simulated values, and the black lines is the simulation area. The same applies to Figures 3 and 4.

Table 2 shows the calculated correlation coefficients and RMSEs, in which the correlation coefficients are calculated by Formula 3, and RMSEs are calculated by Formula 4 . Both the simulated value and the observed value are multi-year averages. Combined with Table 2, it can be found that the model can well simulate the annual average, maximum and minimum temperatures, and the simulation results of the four schemes for each temperature factor do not differ significantly. Moreover, the correlation coefficients between the simulated and observed annual average and minimum temperatures are the same in the four schemes. However, we find that the RUN2 scheme has the lowest RMSE in the annual average and minimum temperature simulations, which means that this scheme has the best performance in simulating temperature. For the simulation of the maximum temperature, the CORREL do not differ greatly. In this case, we still choose the scheme with the lowest RMSE as the optimal scheme.

\subsubsection{The Analysis of Average Annual Precipitation}

As can be seen from Figure 3, the three parameterization schemes and sets of the model can reflect the distribution of precipitation in the western Tianshan Mountains of Xinjiang, China. The precipitation at the edge of the region is higher than that in the middle of the region, and it is closely related to the terrain. Generally, it is consistent with the law that the precipitation is higher in the mountain area than in the basin, higher in the basin than in the center of the basin, and higher in the windward slope of the mountain area than the leeward slope. On the whole, the precipitation distribution simulated by the model is consistent with the impact of the actual terrain on the precipitation in the western Tianshan Mountains, where the precipitation is scarce and the climate is dry. Combined with Table 2, 
it is found that the CORREL and RMSE of RUN1, RUN3 and ENS schemes are the same, and all of them are better than the RUN2 schemes.
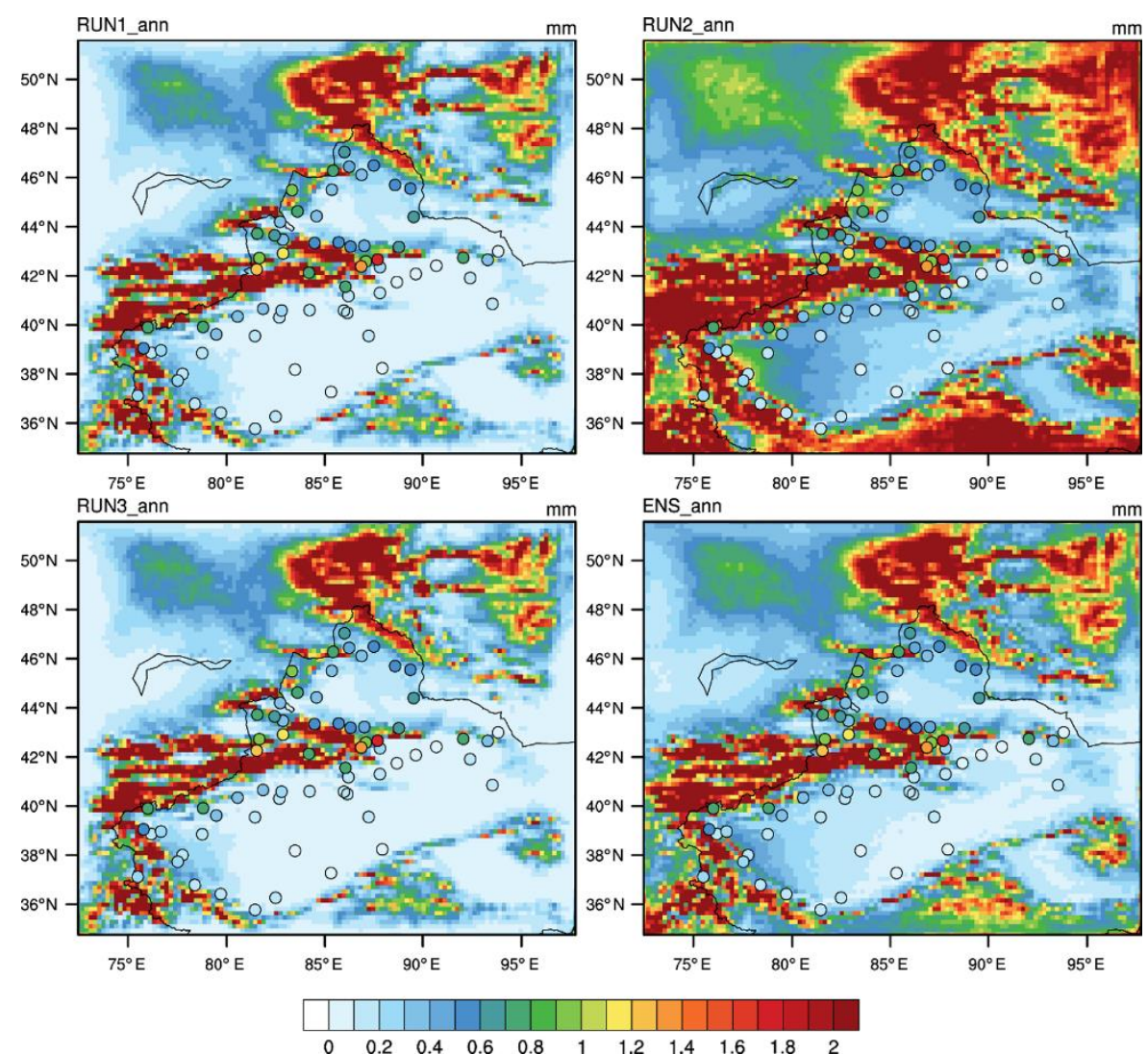

Figure 3. Comparison between simulation and observation of precipitation using four cumulus parameterization schemes.
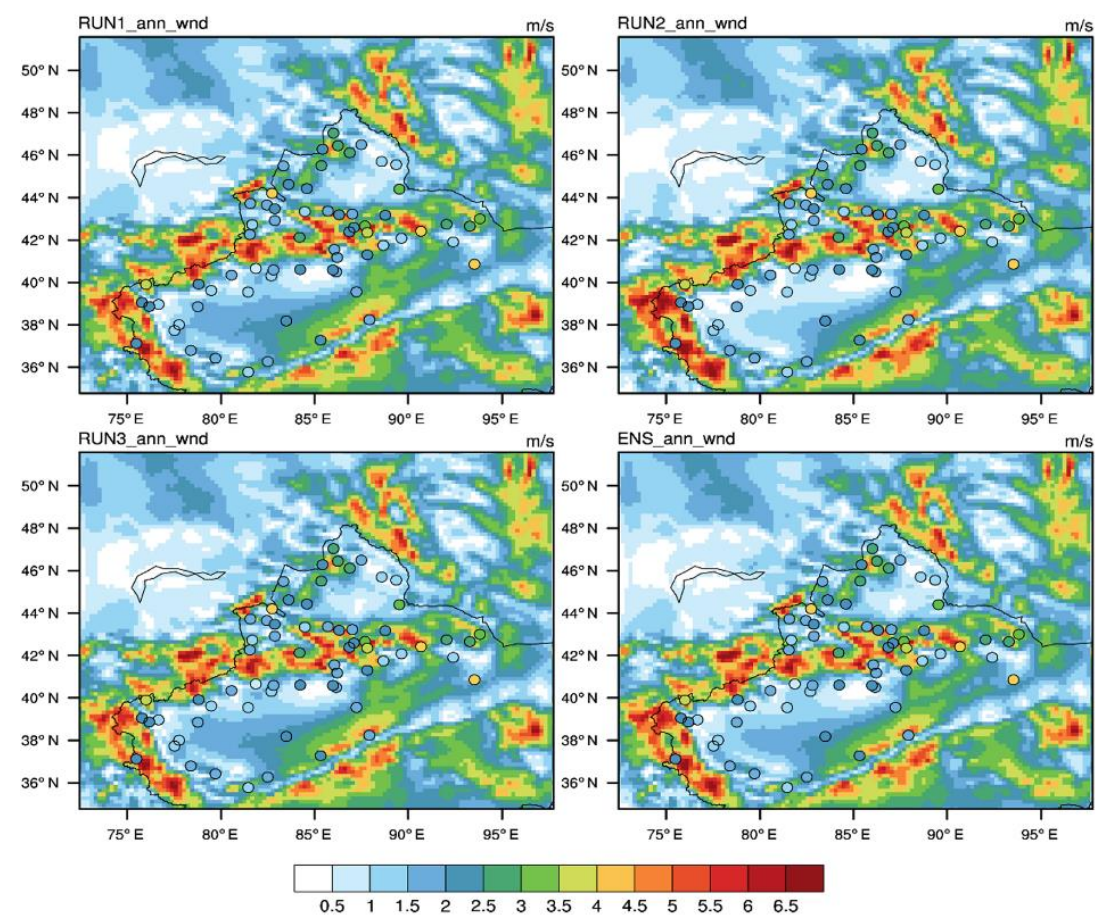

Figure 4. Comparison between simulated and observed wind speeds using four parameterization schemes. 
Table 2. CORREL and RMSE of temperature, precipitation and wind speed simulated by different parameterization schemes; the units for the RMSE of temperature, precipitation and wind speed are ${ }^{\circ} \mathrm{C}, \mathrm{mm}$ and $\mathrm{m} / \mathrm{s}$, respectively.

\begin{tabular}{cccc}
\hline Meteorological Factors & Parameterization Schemes & Correlation Coefficient & Root Mean Square Error \\
\hline \multirow{4}{*}{ Average annual temperature } & RUN1_ann & 0.8 & 4.8 \\
& RUN2_ann & 0.8 & 4.5 \\
& RUN3_ann & 0.8 & 4.8 \\
& ENS_ann & 0.8 & 4.7 \\
Maximum temperature & RUN1_maxTemp & 0.9 & 5.2 \\
& RUN2_maxTemp & 0.8 & 4.9 \\
& RUN3_maxTemp & 0.9 & 5.2 \\
ENS_maxTemp & 0.8 & 5.1 \\
Minimum temperature & RUN1_minTemp & 4.4 \\
& RUN2_minTemp & 4.1 \\
& RUN3_minTemp & 0.7 & 4.4 \\
Precipitation & ENS_minTemp & 0.7 & 4.3 \\
& RUN1_ann & 0.7 & 0.7 \\
& RUN2_ann & 0.4 & 0.7 \\
Wind speed & RUN3_ann & 0.2 & 0.9 \\
& ENS_ann & 0.4 & 0.7 \\
& RUN1_ann_wnd & 0.4 & 0.7 \\
\hline
\end{tabular}

\subsubsection{The Analysis of Average Annual Wind Speed}

In Figure 4, we find that there is no difference between simulation and observation among the four schemes. Combined with Table 2, it is found that the CORREL and RMSE of wind speed simulations also have no difference among the four schemes. The main reason for this situation is that the wind speed is highly uncertain.

\subsubsection{The Results of Annual Simulation}

Through the analysis in Sections 4.1.1-4.1.3, we draw the conclusion in Table 3. In the simulation of western Tianshan Mountains in Xinjiang, China, the RUN2 scheme is selected for temperature, maximum temperature and minimum temperature, which can make the simulation results better and closer to the observed values. The RUN1, RUN3 and ENS scheme is selected for annual precipitation, and all schemes are the same for wind speed simulation

Table 3. The optimal scheme of different meteorological factors in the simulation area.

\begin{tabular}{cc}
\hline Simulation Parameter & Optimal Scheme \\
\hline Average temperature & RUN2 \\
Maximum temperature & RUN2 \\
Minimum temperature & RUN2 \\
Annual precipitation & RUN1/RUN3/ENS \\
Wind speed & RUN1/RUN2/RUN3/ENS \\
\hline
\end{tabular}

\subsection{RegCM Seasonal Numerical Simulation and Inspection}

Four schemes are used to simulate the meteorological factors in four seasons in the western Tianshan Mountains of Xinjiang, China. The simulated and observed CORREL and RMSE are obtained, as shown in Tables 4 and 5, respectively. 
Table 4. The CORREL of seasonal simulation and observation.

\begin{tabular}{|c|c|c|c|c|c|}
\hline Meteorological Factors & Parametrization Schemes & Spring & Summer & Autumn & Winter \\
\hline \multirow{4}{*}{ Mean Temperature } & RUN1 & 0.8 & 0.8 & 0.8 & 0.7 \\
\hline & RUN2 & 0.8 & 0.8 & 0.8 & 0.6 \\
\hline & RUN3 & 0.8 & 0.8 & 0.8 & 0.7 \\
\hline & ENS & 0.8 & 0.8 & 0.8 & 0.7 \\
\hline \multirow{4}{*}{ Maximum Temperature } & RUN1 & 0.9 & 0.8 & 0.9 & 0.7 \\
\hline & RUN2 & 0.8 & 0.8 & 0.9 & 0.6 \\
\hline & RUN3 & 0.9 & 0.8 & 0.9 & 0.7 \\
\hline & ENS & 0.9 & 0.8 & 0.9 & 0.7 \\
\hline \multirow{4}{*}{ Minimum Temperature } & RUN1 & 0.8 & 0.7 & 0.7 & 0.6 \\
\hline & RUN2 & 0.7 & 0.7 & 0.7 & 0.5 \\
\hline & RUN3 & 0.8 & 0.7 & 0.7 & 0.6 \\
\hline & ENS & 0.8 & 0.7 & 0.7 & 0.6 \\
\hline \multirow{4}{*}{ Annual Precipitation } & RUN1 & 0.4 & 0.4 & 0.3 & 0.5 \\
\hline & RUN2 & 0.2 & 0.3 & 0.1 & 0.2 \\
\hline & RUN3 & 0.4 & 0.4 & 0.3 & 0.5 \\
\hline & ENS & 0.4 & 0.4 & 0.2 & 0.5 \\
\hline \multirow{4}{*}{ Wind Speed } & RUN1 & 0.4 & 0.4 & 0.4 & 0.2 \\
\hline & RUN2 & 0.4 & 0.4 & 0.4 & 0.2 \\
\hline & RUN3 & 0.4 & 0.4 & 0.4 & 0.2 \\
\hline & ENS & 0.4 & 0.4 & 0.4 & 0.2 \\
\hline
\end{tabular}

Table 5. The RMSE of seasonal simulation and observation. the units for the RMSE of temperature, precipitation and wind speed are ${ }^{\circ} \mathrm{C}, \mathrm{mm}$ and $\mathrm{m} / \mathrm{s}$, respectively.

\begin{tabular}{|c|c|c|c|c|c|}
\hline Meteorological Factors & Parametrization Schemes & Spring & Summer & Autumn & Winter \\
\hline \multirow{4}{*}{ Mean Temperature } & RUN1 & 5.4 & 5.4 & 4.6 & 4.7 \\
\hline & RUN2 & 5.1 & 5.3 & 4.4 & 4.1 \\
\hline & RUN3 & 5.4 & 5.4 & 4.6 & 4.7 \\
\hline & ENS & 5.3 & 4.4 & 4.5 & 4.4 \\
\hline \multirow{4}{*}{ Maximum Temperature } & RUN1 & 5.9 & 5.5 & 5.1 & 5.6 \\
\hline & RUN2 & 5.6 & 5.4 & 5.0 & 4.8 \\
\hline & RUN3 & 5.9 & 5.5 & 5.1 & 5.6 \\
\hline & ENS & 5.8 & 5.4 & 5.1 & 5.2 \\
\hline \multirow{4}{*}{ Minimum Temperature } & RUN1 & 4.7 & 5.2 & 4.2 & 4.4 \\
\hline & RUN2 & 4.5 & 5.0 & 4.0 & 3.9 \\
\hline & RUN3 & 4.7 & 5.2 & 4.2 & 4.4 \\
\hline & ENS & 4.6 & 5.1 & 4.1 & 4.1 \\
\hline \multirow{4}{*}{ Annual Precipitation } & RUN1 & 0.7 & 1.3 & 0.6 & 0.3 \\
\hline & RUN2 & 1.0 & 1.5 & 0.8 & 0.3 \\
\hline & RUN3 & 0.7 & 1.3 & 0.6 & 0.3 \\
\hline & ENS & 0.7 & 1.2 & 0.6 & 0.3 \\
\hline \multirow{4}{*}{ Wind Speed } & RUN1 & 1.4 & 1.4 & 1.3 & 1.5 \\
\hline & RUN2 & 1.4 & 1.4 & 1.3 & 1.6 \\
\hline & RUN3 & 1.4 & 1.4 & 1.3 & 1.5 \\
\hline & ENS & 1.4 & 1.4 & 1.3 & 1.5 \\
\hline
\end{tabular}

The RegCM4.5 model was used to simulate seasonal meteorological factors in the western Tianshan Mountains from 2012 to 2016. From Table 4, we can see that the correlation coefficients of the four schemes for the simulation of the mean and maximum temperatures are higher in spring, summer and autumn, and the values are greater than 0.8 . Here, we choose the scheme with lower RMSE as the optimal one. In the simulation of the minimum temperature in four seasons, the correlation coefficients are lower than those of the mean and maximum temperatures, and their RMSEs are also relatively low. In the simulation of 
annual precipitation and wind speed of four schemes, the correlation coefficients are lower than those of the temperature simulations. Combined with Tables 4 and 5, the optimal schemes for the four-seasons simulations are shown in Table 6.

Table 6. The optimal solution for different meteorological factors in spring, summer, autumn and winter.

\begin{tabular}{ccccc}
\hline Parameterzation Schemes & Spring & Summer & Autumn & Winter \\
\hline Temperature & RUN2 & ENS & RUN2 & RUN2 \\
Maximum Temperature & RUN2 & RUN2/ENS & RUN2 & RUN2 \\
Minimum Temperature & RUN2 & RUN2 & RUN2 & RUN2 \\
Precipitation & RUN1/RUN3/ENS & ENS & RUN1/RUN3/ENS & ALL \\
Wind Speed & ALL & ALL & ALL & RUN1/RUN3/ENS \\
\hline
\end{tabular}

\section{Conclusions}

In this study, we used the regional climate model RegCM4.5 and selected different cumulus parameterization schemes to simulate annual and seasonal meteorological factors in the western Tianshan Mountains region of Xinjiang from 2012 to 2016, and investigate the applicability of different cumulus parameterization schemes to regional climate simulations. The evaluation of the experimental results shows that: (1) In the annual simulations, the RUN2 scheme performs best in simulating the average, maximum and minimum temperatures, indicating that the RUN2 scheme is more suitable for the simulation of temperature, while the other three schemes perform better in simulating precipitation. In the simulation of wind speed, there is no difference among the four schemes. (2) In the simulation of four seasons, the RUN2 scheme still performs better in the simulation of average, maximum and minimum temperatures in four seasons, except for the simulation of average temperature in spring and summer. In the simulation of the maximum temperature in summer, the RUN2 scheme is the same as that of ENS. In the simulation of precipitation, all other schemes perform better than the RUN2 scheme. In the simulation of wind speed, there is no difference among the four schemes in spring, summer, autumn and winter. In the simulation of winter, other schemes perform better than the RUN2 scheme.

This study provides additional information for the selection of available accurate cumulus parameterization simulation scheme for regional climate simulation in western Tianshan Mountains, Xinjiang, which effectively solves the problem of inaccurate simulation caused by random selection of cumulus parameter schemes. However, there are still some problems, for example, the current simulation time span is relatively short due to the limitation of the data collected from the observation sites, and we will collect more observation data later and lengthen the simulation period in the future.

Author Contributions: Conceptualization, Methodology, Validation, Formal Analysis, Q.C. and F.L.; Software, Q.C. and F.L.; supervision, Q.C. and F.L.; Funding Acquisition, F.L.; Writing-original draft preparation, Q.C. and F.L.; Writing-review and editing, Q.C. and F.L. All authors have read and agreed to the published version of the manuscript.

Funding: This research was funded by National Science and Technology Major Project of China's High Resolution Earth Observation System (grant numbers: 21-Y30B02-9001-19/22).

Data Availability Statement: The data presented in this study are available in Section 3.2.

Acknowledgments: Thanks to NCEP/NCAR for providing reanalysis data, and thanks to China Meteorological Data Network for providing observation data.

Conflicts of Interest: The authors declare no conflict of interest.

\section{References}

1. Zhou, X.; Huang, G.; Piwowar, J.; Fan, Y.; Wang, X.; Li, Z.; Cheng, G. Hydrologic Impacts of Ensemble-RCM-Projected Climate Changes in the Athabasca River Basin, Canada. J. Hydrometeorol. 2018, 19, 1953-1971. [CrossRef]

2. Shi, Y.; Wang, G.; Gao, X. Role of resolution in regional climate change projections over China. Clim. Dyn. 2018, 51, 2375-2396. [CrossRef] 
3. Grassi, B.; Redaelli, G.; Visconti, G. Arctic Sea Ice Reduction and Extreme Climate Events over the Mediterranean Region. J. Clim. 2013, 26, 10101-10110. [CrossRef]

4. Díez, E.; Orfila, B.; Frías, M.D.; Fernández, J.; Cofiño, A.S.; Gutiérrez, J.M. Downscaling ECMWF seasonal precipitation forecasts in Europe using the RCA model. Tellus A Dyn. Meteorol. Oceanogr. 2011, 63, 757-762. [CrossRef]

5. Sangelantoni, L.; Ricchi, A.; Ferretti, R.; Redaelli, G. Dynamical Downscaling in Seasonal Climate Forecasts: Comparison between RegCM- and WRF-Based Approaches. Atmosphere 2021, 12, 757. [CrossRef]

6. Llopart, M.; da Rocha, R.P.; Reboita, M.; Cuadra, S. Sensitivity of simulated South America climate to the land surface schemes in RegCM4. Clim. Dyn. 2017, 49, 3975-3987. [CrossRef]

7. Chung, J.X.; Juneng, L.; Tangang, F.; Jamaluddin, A.F. Performances of BATS and CLM land-surface schemes in RegCM4 in simulating precipitation over CORDEX Southeast Asia domain. Int. J. Clim. 2018, 38, 794-810. [CrossRef]

8. Ali, S.; Dan, L.; Congbin, F.U.; Yang, Y. Performance of Convective Parameterization Schemes in Asia Using RegCM: Simu-la-tions in Three Typical Regions for the Period 1998-2002. Adv. Atmos. Sci. 2015, 5, 141-156. [CrossRef]

9. Koné, B.; Diedhiou, A.; Touré, N.E.; Sylla, M.B.; Kobea, A.T. Sensitivity study of the regional climate model RegCM4 to dif-ferent convective schemes over West Africa. Earth Syst. Dyn. 2018, 9, 1261-1278. [CrossRef]

10. Bhatla, R.; Mandal, B.P.; Verma, S.; Ghosh, S.; Mall, R.K. Performance of Regional Climate Model in Simulating Monsoon Onset Over Indian Subcontinent. Pure Appl. Geophys. 2018, 176, 409-420. [CrossRef]

11. Bhatla, R.; Ghosh, S.; Mall, R.K.; Sinha, P.; Sarkar, A. Regional Climate Model Performance in Simulating Intra-seasonal and Interannual Variability of Indian Summer Monsoon. Pure Appl. Geophys. 2018, 175, 3697-3718. [CrossRef]

12. Zanis, P.; Douvis, C.; Kapsomenakis, I.; Kioutsioukis, I.; Melas, D.; Pal, J.S. A sensitivity study of the Regional Climate Model (RegCM3) to the convective scheme with emphasis in central eastern and southeastern Europe. Theor. Appl. Clim. 2009, 97, 327-337. [CrossRef]

13. Tchotchou, L.; Kamga, F.M. Sensitivity of the simulated African monsoon of summers 1993 and 1999 to convective parameterization schemes in RegCM3. Theor. Appl. Climatol. 2010, 100, 207-220. [CrossRef]

14. Raju, P.V.S.; Bhatla, R.; Almazroui, M.; Assiri, M. Performance of convection schemes on the simulation of summer monsoon features over the South Asia CORDEX domain using RegCM-4.3. Int. J. Clim. 2015, 35, 4695-4706. [CrossRef]

15. Zhang, S.; Lu, S.; Bao, Y.; Ma, D. Sensitivity of precipitation over China to different cumulus parameterization schemes in RegCM4. J. Meteorol. Res. 2015, 29, 119-131. [CrossRef]

16. Pal, J.S.; Giorgi, F.; Bi, X.; Elguindi, N.; Solmon, F.; Rauscher, S.A.; Steiner, A.L. Regional climate modeling for the develop-ing world: The ICTP RegCM3 and RegCNET. Bull. Am. Meteorol. Soc. 2007, 88, 1395-1409. [CrossRef]

17. Pieczka, I.; Pongrácz, R.; André, K.S.; Kelemen, F.D.; Bartholy, J. Sensitivity analysis of different parameterization schemes using RegCM4.3 for the Carpathian region. Theor. Appl. Clim. 2016, 130, 1175-1188. [CrossRef]

18. Gadzhev, G.; Ivanov, V.; Ganev, K.; Chervenkov, H. TVRegCM Numerical Simulations-Preliminary Results. In International Conference on Large-Scale Scientific Computing; Springer: Cham, Switzerland, 2018; pp. 266-274.

19. Patari, M.; Brankovi, E. Skill of 2-m Temperature Seasonal Forecasts over Europe in ECMWF and RegCM Models. Mon. Weather Rev. 2012, 140, 1326-1346. [CrossRef]

20. Sangelantoni, L.; Ferretti, R.; Redaelli, G. Toward a Regional-Scale Seasonal Climate Prediction System over Central Italy based on Dynamical Downscaling. Climate 2019, 7, 120. [CrossRef]

21. Grell, G.A. Prognostic Evaluation of Assumptions Used by Cumulus Parameterizations. Mon. Weather Rev. 1993, 121, 764-787. [CrossRef]

22. Fritsch, M.; Chappell, C.F. Numerical prediction of convectively driven mesoscale pressure systems. Part I: Convective parameterization. Atmos. Sci. 1980, 37, 1722-1733. [CrossRef]

23. Giorgi, F.; Bates, G.T. The climatological skill of a regional model over complex terrain. Mon. Weather Rev. 1989, 117, 2325-2347. [CrossRef]

24. Dickinson, R.E.; Errico, R.M.; Giorgi, F.; Bates, G.T. A regional climate model for the western United States. Clim. Chang. 1989, 15, 383-422. [CrossRef]

25. Giorgi, F.; Marinucci, M.R.; Bates, G.T. Development of a second generation regional climate model (RegCM2). Part I. Boundary layer and radiative transfer processes. Mon. Weather Rev. 1993, 121, 2794-2813. [CrossRef]

26. Pal, J.S.; Small, E.; Eltahir, E.A.B. Simulation of regional-scale water and energy budgets: Representation of subgrid cloud and precipitation processes within RegCM. J. Geophys. Res. 2000, 105, 29579-29594. [CrossRef]

27. Giorgi, F.; Coppola, E.; Solmon, F.; Mariotti, L.; Sylla, M.B.; Bi, X.; Brankovic, C. RegCM4: Model description and preliminary tests over multiple CORDEX domains. Clim. Res. 2012, 52, 7-29. [CrossRef]

28. Grell, G.; Dudhia, J.; Stauffer, D. Description of the Fifth Generation Penn State/NCAR Mesoscale Model (MM5); Ncar Technical Note: Boulder, CO, USA, 1994; p. 121.

29. Holtslag, A.; Bruijn, E.; Pan, H.L. A High Resolution Air Mass Transformation Model for Short-Range Weather Forecasting. Mon. Weather Rev. 1990, 188, 1561-1575. [CrossRef]

30. Oleson, K.W.; Niu, G.-Y.; Yang, Z.-L.; Lawrence, D.; Thornton, P.; Lawrence, P.J.; Stöckli, R.; Dickinson, R.E.; Bonan, G.B.; Levis, S.; et al. Improvements to the Community Land Model and their impact on the hydrological cycle. J. Geophys. Res. 2008, 113, 1021-1026. [CrossRef] 
31. Kiehl, J.T.; Hack, J.J.; Bonan, G.B.; Boville, B.A.; Briegleb, B.P. Description of the NCAR Community Climate Model (CCM3). Ncar Tech. Note 1996, 108, 55-60.

32. Giorgi, F.; Coppola, E.; Solmon, F.; Mariotti, L.; Sylla, M.B.; Bi, X.; Elguindi, N.; Diro, G.T.; Nair, V.; Giuliani, G.; et al. RegCM4: Model description and preliminary tests over multiple CORDEX domains. Clim. Res. 2011, 936, 577X.

33. Giorgi, F.; Marinucci, M.R.; Bates, G.T. Development of a 2nd-Generation Regional Climate Model (Regcm2). Part2. Con-vec-tive Processes and Assimilation of Lateral Boundary Conditions. Mon. Weather Rev. 1993, 121, 2814-2832. [CrossRef]

34. Tiedtke, M. A comprehensive mass-flux scheme for cumulus parameterization in large-scale models. Mon. Weather Rev. 1989, 117, 1779-1800. [CrossRef]

35. Emanuel, K.A. A Scheme for Representing Cumulus Convection in Large-Scale Models. J. Atmos. Sci. 1991, 48, 2313-2329. [CrossRef]

36. Emanuel, K.; Marina, R. Development and Evaluation of a Convection Scheme for Use in Climate Models. J. Atmos. Sci. 1999, 56, 1766-1782. [CrossRef]

37. Kalnay, E.; Kanamitsu, M.; Kistler, R.; Collins, W.; Deaven, D.; Gandin, L.; Iredell, M.; Saha, S.; White, G.; Woollen, J.; et al. The NCEP/NCAR 40-Year Reanalysis Project. Renew. Energy 2018, 74, 146-194. [CrossRef]

38. Kistler, R.; Kalnay, E.; Collins, W.; Saha, S.; White, G.; Woollen, J.; Chelliah, M.; Ebisuzaki, W.; Kanamitsu, M.; Kousky, V.; et al. The NCEP/NCAR 50-year reanalysis: Monthly means CD-ROM and documentation. Bull. Am. Meteorol. Soc. 2001, 82, 247-268. [CrossRef]

39. Torma, C.Z. Detailed validation of EURO-CORDEX and Med-CORDEX regional climate model ensembles over the Carpa-thian Region. Idojaras 2019, 123, 217-240.

40. Kotlarski, S.; Keuler, K.; Christensen, O.B.; Colette, A.; Déqué, M.; Gobiet, A.; Goergen, K.; Jacob, D.; Lüthi, D.; van Meijgaard, E.; et al. Regional climate modeling on European scales: A joint standard evaluation of the EURO-CORDEX RCM ensemble. Geosci. Model Dev. 2014, 7, 1297-1333. [CrossRef] 